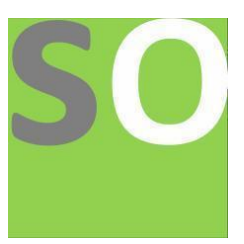

Article title: Level of Perceived Satisfaction with Acute Pain Management among the Patients with Fracture of Long Bones in Teaching Hospital Jaffna

Authors: Heerthikan Kanagalingam[1], Thivera Murukananthan[2]

Affiliations: Faculty of Medicine, University of Jaffna[1]

Orcid ids: 0000-0001-6628-7356[1]

Contact e-mail: 2016fm034@univ.jfn.ac.Ik

License information: This work has been published open access under Creative Commons Attribution License http://creativecommons.org/licenses/by/4.0/, which permits unrestricted use, distribution, and reproduction in any medium, provided the original work is properly cited. Conditions, terms of use and publishing policy can be found at https://www.scienceopen.com/.

Preprint statement: This article is a preprint and has not been peer-reviewed, under consideration and submitted to ScienceOpen Preprints for open peer review.

DOI: 10.14293/S2199-1006.1.SOR-.PPOWAL2.v1

Preprint first posted online: 27 January 2022

Keywords: Acute pain management, patient's perceived satisfaction, hip fractures, long bone fracture, socio demographic and health related factors 


\section{Level of Perceived Satisfaction with Acute Pain Management among the Patients with Fracture of Long Bones in Teaching Hospital Jaffna}

Heerthikan $\mathrm{K}^{* 1}$, Jayalath $\mathrm{NT}^{1}$, Thivera $\mathrm{M}^{1}$, Wanninayaka $\mathrm{WMOG}^{1}$, Pavithra $\mathrm{M}^{1}$, Coonghe $\mathrm{PAD}^{2}$, Ambalavanar $\mathrm{DC}^{3}$

${ }^{1}$ Faculty of Medicine, University of Jaffna.

${ }^{2}$ Department of Community and Family Medicine, Faculty of Medicine, University of Jaffna.

${ }^{3}$ Department of Surgery, Faculty of Medicine, University of Jaffna

\section{Introduction}

Pain is an unpleasant sensation that has to be managed properly. In fracture patients, effective pain management plays a major role in their treatment. Although much efforts are put in by the doctors, there is uncertainty about the level of satisfaction with acute pain management. We hope to assess the level of satisfaction with acute pain management among fracture patients and the results could be used to improve the level of satisfaction in the future.

\section{Objectives}

To assess the level of perceived satisfaction with acute pain management and associated sociodemographic and health related factors among patients with long bones fractures in surgical casualty ward of Teaching Hospital Jaffna.

\section{Methodology}

An institutional based descriptive cross-sectional study was conducted at ward 24, Teaching Hospital, Jaffna. This study was conducted from October 2020 to March 2021. Data was collected through interviewer-administrated questionnaires from patients above 12 years of age with fractures of long bones who had undergone management within 12 hours of admission and analyzed with SPSS 21 (T-test and ANOVA). Femoral neck, intertrochanteric, subtrochanteric and femoral head fractures were grouped as hip fractures for ease of analysis. Perceived satisfaction score was calculated according to the participant's answers to 11 Likert scale 
questions which were selected from The Pain Treatment Satisfaction Scale (PTSS), each scoring from 0 to 3. (Overall score 0 to 33) Numerical pain scale was used to assess the level of pain.

\section{Results}

Among 120 study participants, 70 were male and 50 were female. The median pain score immediately after fracture was 8 , one hour after analgesic administration was 5 and after nonmedical intervention following analgesic administration was 4 . There was a significant association with the patient's satisfaction and time taken for initial administration of analgesics $(p=0.46)$, site of fracture (clavicle $\mathrm{p}=0.005$ ) and type of non-medical intervention (pop cast $\mathrm{p}=0.049$, intervention $\mathrm{p}=0.011$ ). There were no significant association between patient's perceived satisfaction with gender $(\mathrm{p}=0.218)$, age category $(\mathrm{p}=0.935)$, educational level $(\mathrm{p}=0.130)$, marital status $(\mathrm{p}=0.095)$, past medical history $(\mathrm{p}=0.957)$ and past surgical history $(\mathrm{p}=0.227)$.

\section{Conclusion}

Majority of the patients were satisfied with the acute pain management. Early onset analgesics administration \& non-medical interventions and lower level of patient's expectation regarding pain management in our community were the reasons for higher overall satisfaction.

\section{Keywords}

Acute pain management, patient's perceived satisfaction, hip fractures, long bone fracture, socio demographic and health related factors, Teaching hospital Jaffna 


\section{Introduction}

\subsection{Background}

The International Association for the Study of Pain (IASP) defines pain as "an unpleasant sensory and emotional experience associated with actual or potential tissue damage, or described in terms of such damage.(IASP Terminology - IASP, 2017)

Pain assessment is a multidimensional observational assessment of a patient's experience of pain. Many factors influencing pain perception could be categorized into developmental factors (e.g. age, cognitive development), physiological factors (e.g. fatigue, genes, ethnicity, neurological functioning), social factors (e.g. social attention, previous experience, family and social support), spiritual factors(e.g. religion / faith), psychological factors (e.g. anxiety, depression and coping style, cultural factors (e.g. ethnicity) and financial factors (e.g. cost of care), etc.(Joel et al., 2015)

Based on duration of persistence, pain can be classified as acute and chronic. Here, we are focusing on acute pain, which may be assessed by descriptive statements of patients and pain intensity using numeric rating scales.(Breivik et al., 2008) Pain relief has been recognized as a human right.(IASP Terminology - IASP, 2017)

Effective pain management is an essential component of the care of fracture patients, and generally involves reducing or eliminating pain and discomfort with minimal side effects.(Roozekrans et al., 2018) As it results in improved patient outcomes and increased patient satisfaction. Acute orthopedic pain management may involve various interventions in addition to using analgesics for pain relief. Improved interventions can enhance patients' attitudes and perceptions of pain. What a patient believes and understands about pain is critical in influencing the patients' reaction to the pain therapy provided. Use of interdisciplinary pain teams can lead to improvements in patients' pain management, outcomes and satisfaction.(Glowacki, 2015)

Thus, organized orthopedic pain management is a major part of successful patient treatment.(Schulz and Jerosch, 2007) Patient pain management is a "big part of patient satisfaction". Patient satisfaction with pain management is however, a relatively neglected area in Sri Lanka.

\subsection{Justification}

As medical students, we observed that patients with fractures complained about pain following admission as well as after some interventions at Teaching Hospital, Jaffna. Pain is one of 
nature's ways of warning us that something is going wrong in our body. It is a really uncomfortable sensation of varying intensity which may lead to several complications and interfere with day-to-day life. So, treating pain is an essential part of patient management.

Although much effort is put by the doctors and staff members on reducing the pain, there is an uncertainty about the level of satisfaction with acute pain management among the patients with fractures of long bones. We had selected a descriptive cross sectional study to assess perceived satisfaction with pain management because it was an undergraduate study and we had limited time and resources. We selected the study population as patients with long bones because long bones fractures are common in our community; thereby we were able to get an adequate number of patients within a limited time. We had selected the numerical pain scale as our study tool to assess the level of pain because it is simple and sensitive to small changes in pain.

By doing this study we hope to assess level of satisfaction with acute pain management among fracture patients and to derive guidelines which could be used at Teaching Hospital Jaffna to improve the level of satisfaction with acute pain management. As there were no similar previous studies, this may also provide a basis for future research as well.

\section{Objectives}

\section{General objective}

To assess the level of perceived satisfaction with acute pain management and the influence of socio-demographic and health related factors on it among patients with fractures in long bones in general surgical wards and orthopedic wards of Teaching Hospital Jaffna

\section{Specific objectives}

- To assess the level of perceived satisfaction with the pain management among patients with fractures of long bones in general surgical wards and orthopedic wards of Teaching Hospital Jaffna.

- To describe the association between socio-demographic factors and level of perceived satisfaction with pain management among patients with fractures in long bones.

- To describe the association between health-related factors and level of perceived satisfaction with pain management among patients with fractures in long bones.

\section{Literature Review}

Systematic literature searching is a critical component of a research study as it involves a systematic search for other studies related to our study. We used the following search engines such as PubMed, Google Scholar, ncbi.nlm.gov and Research Gate for our study. While we 
were doing our literature search, we used keywords such as "long bone fractures", "hip fractures", "pain management", "patients' satisfaction", "socio demographic factors" and "health related factors" to find out similar studies.

\subsection{Patient satisfaction of pain management in fractures}

Pain management is a major concern for patients as pain impairs patients' treatment and recovery, especially in orthopedic patients. Patient's satisfaction with pain management is vital in measuring the success of health care institutions. A study carried out among thirty American and thirty Dutch patients after operative treatment of ankle fractures revealed that patients who used non opioid pain medication report less pain and greater satisfaction with the pain relief than patients managed with opioid pain medication.(Helmerhorst et al., 2012)

A cross-sectional study was conducted in Lebanon targeting two different populations who were most likely to have experienced acute non cancer pain. Among the orthopedic patients, $10.7 \%$ were dissatisfied with pain management. The dissatisfied patients were those who did not have their pain assessed; those who were not informed to report it when in pain and those who did not receive pain medications on time.(Ramia et al., 2017)

A study was done on perceived control mediates the relationship between pain severity and patient satisfaction. They concluded that the perception of how well the pain could be controlled was more closely associated with the amount of pain relief than the severity of the pain. Self-efficacy and coping skills have a strong relationship between the severity of pain and the individual's response to the pain which determines patient satisfaction with pain management. The experience and expectations of the patient also influences the level of satisfaction. As older people have more experience and less expectations, they are more satisfied than young people.(Pellino and Ward, 1998)

A study was performed on the influence of expectations and actual pain experiences on satisfaction with postoperative pain management in 191 patients. Only $8 \%$ were dissatisfied. Main characteristics of dissatisfied patients were younger age and female sex.(Svensson, Sjöström and Haljamäe, 2001)

A study done in South Africa involving 270 patients with long bone fractures says that $2 \%$ of patients were not asked about the pain intensity while $18 \%$ were asked initially by a nurse only. Further says $60 \%$ recalled their pain severity as 5 or more on a visual scale and no association between the severity and analgesics prescribed.(Awolola, Campbell and Ross, 2015)

A study in America indicated that nursing care, physician care, staff care and hospital facility were not equally influential on patient satisfaction in pain management and suggested 
improving nursing and staff care to provide more direct care for patients with pain.(Otani et al., 2015)

A randomized trial was conducted with a total of 68 patients with hip fracture in a tertiary care hospital in Turkey comparing the pain management patient satisfaction, comfort and preoperative complication of using position splint versus skin traction conclude using position splint over skin traction is significant. $(\mathrm{P}<0.05)$. (Tosun, Aslan and Tunay, 2018)

Patients' satisfaction with treatment is crucial to measure performance and success of the healthcare setting. In fact, patients expect to receive optimal pain management resulting in fewer adverse effects; says a cross-sectional study conducted in two tertiary care hospitals. It is found around $85 \%$ of the patients were satisfied with their pain management. Pain intensity documentation by healthcare professionals was found in $41.5 \%$ of the cases and $7.7 \%$ of the patients had to wait for more than 30 minutes before getting the pain medication.(Tawil, Iskandar and Salameh, 2018)

Culture is another factor influencing patient satisfaction with pain management. This is evident in narcotic opioid usage. "Pain and satisfaction with pain relief are culturally mediated. Patients that use non-opioid pain medication report less pain and greater satisfaction with pain relief than patients managed with opioid pain medication."(Helmerhorst et al., 2012)

Another study says, after operative fracture treatment, patients who take more opioids report greater pain intensity and less satisfaction with pain relief. Greater self-efficacy was the best determinant of satisfaction with pain relief(Bot et al., 2014) on opioids usage.

Giving adequate information to patients, especially according to their knowledge is another vital factor influencing the satisfaction. A study carried out in 24 patients with clavicle fracture in Netherlands states that informing patients about their injury, treatment options and expectations for recovery is paramount for overall patient satisfaction after treatment for a displaced mid shaft clavicle fracture. (Tutuhatunewa et al., 2020)

\subsection{Influence of socio-demographic factors on patient satisfaction with pain management}

Harvard Medical School USA performed a meta-analysis to examine the relationship of patients' socio-demographic characteristics to their satisfaction with medical care showed that the satisfaction was significantly associated with greater age and less education, and marginally associated with being married and having higher social status. No overall relationship was found for ethnicity, sex or income. Age was the strongest demographic factor for pain satisfaction.(Hall and Dornan, 1990) 
According to a study; demographic characteristics, age, health status, and race consistently had a statistically significant effect on pain satisfaction scores.(Young, Meterko and Desai, 2000) According to the study done by Weiis GL certain predisposing factors like confidence in the community's medical care system, having a regular source of care are more important predictors of patient satisfaction than a patient's age, sex, race, educational attainment, or income.(Weiss, 1988)

A cross-sectional study was done in Iran among patients with chief complaint of pain to assess the influence of socio-demographic and clinical factors of patients on pain relief and satisfaction. They analyzed demographic variables comprised of age, sex, education level, marital status, employment and clinical factors such as medical history of the patient with the data on patient's pain duration, pain intensity, information regarding health care and drug usage for pain relief. They found socio demographic and clinical factors of patients affect patient's sensation of pain, perception of pain there by pain relief and satisfaction.(Hashemi et al., 2016) According to a study on predictors of patient satisfaction and demographic characteristics done in Tehran on 2018 found that patient's demographic factors such as age, marital status significantly affected the patient satisfaction as for example regarding the patient's age, it was found that the younger patients were more satisfied with health services than older ones.(Farrokhi et al., 2020)

A study among an ethnically diverse group of patients with knee osteoarthritis pain suggested that psychosocial and demographic factors influenced the pain scores of patients; hence important determinants of patient satisfaction.(Eberly et al., 2018)

Another study which assessed the pain management measures- analgesic administration, waiting time for analgesia, pain relief and patient's satisfaction in 328 patients (150 women and 178 men, average age $36+/-18$ years) treated for acute musculoskeletal pain. They found that nevertheless, the rates of analgesia administration, waiting time for analgesia, pain relief and patient satisfaction were similar for both genders.(Uri et al., 2015)

A cross-sectional study was conducted at Bhaktapur Hospital of Nepal, to determine the association between various dimensions of patient satisfaction and socio demographic characteristics of the patient. They calculated mean score and percentage of satisfaction across seven dimensions of patient satisfaction. They found Socio demographic factors such as age, gender and ethnicity were associated with general satisfaction of the patient while other socio demographic variables such as education, occupation and religion were associated with most of the dimensions of patient satisfaction and more importantly age was found to be the strong predictor of patient satisfaction in five out of seven dimensions.(Adhikari et al., 2021) 
A study carried out in 2016 showed there was a need for more studies on how cultural, behavioral, and socio-demographic differences affect patient satisfaction, using a standardized questionnaire due to Socio-demographic characteristics were the most varied in the review.(Batbaatar et al., 2017)

According to a study aimed to identify factors associated with satisfaction with care in cancer patients undergoing ambulatory treatment, level of education was not associated with satisfaction scores, although other reports have shown that a higher level of education was associated with higher expectations as regards quality of care.(Nguyen et al., 2011)

Cross-sectional analysis of the 1998 Welsh Health Survey described patient satisfaction varied with socio demographic factors (age, gender, employment status, marital status).(Venn and Fone, 2005)

\subsection{Influence of health related factors on patient satisfaction with pain management}

A study was conducted regarding postoperative numbness and patient satisfaction following plate fixation of clavicle fracture. In this study, they compared differences in numbness, scar satisfaction, pain and overall satisfaction with the operation between those who received a horizontal incision versus those who received a vertical incision. Findings revealed that vertical incision for plate fixation of clavicle shaft fracture may be associated with reduced postoperative numbness and avoid some cases of patient's dissatisfaction.(Wang et al., 2010) A study was conducted on the impact of comorbidity on perioperative outcome of hip fractures in geriatric people. Study results showed that fractures usually occur in patients who have preexisting medical problems or comorbidities. It had been recognized that comorbidity had an influence on treatment and prognosis of the condition.(Menzies et al., 2012)

A study done regarding comorbidity in hip fractures, cost and improving care delivery. It showed that comorbidities appeared to raise the cost of hospitalization and length of hospital stay. The treatment of hip fractures were largely affected by specific comorbidities which also played a role in increasing costs and length of stay. This may influence patient satisfaction.

A population based cross sectional survey in Saudi Arabia was conducted on the association between chronic pain and diabetes/pre diabetes in 2020. They found that in compared to pre diabetic and non-diabetic individuals, people with diabetes had increased prevalence of lower limb pain, back pain, abdominal pain and neck pain. Increased prevalence of chronic pain will also affect the acute pain levels and treatment satisfaction.(Aldossari et al., 2020) 
Another study done in Ethiopia also states there may be an association between previous surgical history and patient satisfaction and the results weren't disclosed.(Belay Bizuneh et al., 2020)

\section{Methodology}

\subsection{Study design}

This was an institutional based descriptive cross sectional study.

\subsection{Study setting}

The study had been conducted at surgery wards and orthopedic ward, Teaching Hospital, Jaffna. Patients with long bones fracture admitted to ward 24 were interviewed after their acute pain management within 12 hours of admission in ward 24 itself or surgery and orthopedic wards. Routine ward works and patient management wasn't interfered or delayed by the study.

\subsection{Study population}

Patients above 12 years of age with fracture of long bones who were admitted and underwent acute management within 12 hours at ward 24, Teaching Hospital, Jaffna were selected.

\subsection{Inclusion criteria}

Patients above 12 years of age with fracture of long bones who underwent any management within 12 hours of admission. The long bone fractures include fractures of humerus, radius, ulna, femur, tibia, fibula and clavicle while femoral neck, intertrochanteric, subtrochanteric and femoral head fractures were grouped as hip fracture. As we had used numerical pain scale, minimum age limit was 12 years old and acute management means any management (medical/surgical/cast/splint/skin traction) done within 12 hours of admission.

\subsection{Exclusion criteria}

Patients who are not in a fit state (unconscious, delirious, severely ill, etc.) to respond to an interview were excluded.

\section{6. $\quad$ Sampling}

\subsubsection{Estimated Sample size}

The sample size was calculated based on the following formula

$n=\frac{Z^{2} P(1-P)}{d^{2}}$

$\mathrm{n}=$ required sample size, 
$\mathrm{Z}=$ confidence level at $95 \%$ (critical value of 1.96),

$\mathrm{p}=$ expected prevalence. As there was no similar study done previously, we are assuming prevalence of satisfaction is $50 \%$

$\mathrm{d}=$ margin of error at $5 \%$ (standard value of 0.05 ),

Thus,

Sample size $(\mathrm{n})=\frac{1.96^{2} \times 0.5(1-0.5)}{(0.05)^{2}}=384.16$

Assuming the non-response rate is $10 \%$

New sample size $=\frac{384.16 \times 100 \%}{90 \%}=427$

\subsubsection{Expected sample size}

Expected number of patients in a four week period is 120 assuming 5 patients per day.

\subsubsection{Sampling Technique}

As the expected number of participants was less than the calculated sample, all the study population were included.

\subsection{Study instrument}

A numeric pain scale, a data extraction form and an interviewer-administered questionnaire were used. The Numeric Pain Scale was incorporated into the questionnaire to assess the level of pain at 5 different instances recalled by the participant. The data extraction form was used to get information on health conditions and ongoing treatment. It was filled using Bed Head Ticket. As we couldn't find any perfect study instrument in various articles, we have developed the questionnaire.

\subsubsection{Development of questionnaire}

The questionnaire was developed by investigators with the support of supervisors using some components from Revised American Pain Society Patient Outcome questionnaire(Gordon et al., 2010) and Pain Treatment Satisfaction Scale.(Evans et al., 2004).

\subsubsection{Validity}

The questionnaire was validated by experts to confirm the appropriateness of the questionnaire for this study. 


\subsubsection{Translation}

The questionnaire was translated from English to Tamil by the experts and that was translated back into English by another expert. Then the first and final questionnaires were compared. The same procedure was done for Sinhala translation.

\subsection{Pilot study}

The pilot study was conducted two weeks before data collection at Ward 24, Teaching Hospital, Jaffna.

\subsection{Data collection}

The study was conducted from October 2020 to March 2021 by interviewing 120 participants. The participants had been recruited with their consent after explaining our research work. On the same day, the scale of pain had been explained to them. It had been done within 12 hours of admission when acute management had finished. The pain score at the admission and 1 hour after acute management and need for more analgesics, satisfaction in various components of the acute pain management, sleep and physical activity during the stay had been asked by the investigators. Basic demographical data (age, sex), information on management and drug information were collected from the Bed Head Ticket. Social distancing and all the standard precautions to ensure hygiene were followed during the whole process. Study period was for 4

\subsection{Data analysis and processing}

The collected data were analyzed, processed and saved with the help of statistical package for social sciences (SPSS 21) from which descriptive analysis (percentage, proportions and measures of central tendency) t-test and ANOVA had been used appropriately. Femoral neck, intertrochanteric, subtrochanteric and femoral head fractures were grouped as hip fracture, age was categorized into adolescence (13-19), young adult (20-35), middle age (36-60) and elder (above 60), Level of pain was categorized into no pain (0), mild pain (1-3), moderate pain (46) and severe pain (7-10) and level of perceived satisfaction was categorized into very satisfied, moderately satisfied, moderately dissatisfied and very dissatisfied and scored 3,2,1,0 for the ease of analysis. Overall satisfaction score was calculated by adding the scores for 11 questions of satisfaction. Marital status was classified as unmarried, married and others. Widow, widower, divorced, separated and living together were included in category "others". For the ease of reporting overall satisfaction was categorized into very satisfied (26-33), moderately satisfied (17-25), moderately dissatisfied (8-16) and very dissatisfied (0-7) 


\subsection{Permissions and Ethical Considerations}

Before the commencement of the research, the proposal was submitted to the ethical review committee, Faculty of Medicine, University of Jaffna through the Department of Community and Family Medicine for the ethical clearance.

Permission to carry out the study were obtained from the Head, Department of Community Medicine and Family Medicine, Faculty of Medicine, University of Jaffna, Director, Teaching Hospital, Jaffna and Consultants Surgeons and Consultant Orthopedic Surgeons in charge for particular casualty days after getting ethical clearance

\subsection{Informed written consent}

The participants of our research were given a clear explanation about the details of the research. Questionnaire and minimal discomfort for the participants during the study was clearly explained to the patients. An informed written consent was obtained from each participant will be obtained to participate in the research and their signature or thumb impression was obtained. For the patients who are under 18 years, the consent from parent or guardian and assent from patient was obtained.

\subsection{Voluntary participation}

The participants have the freedom to withdraw from the study according to their wish without any obligation, before completion of the filling of questionnaire.

\subsection{Privacy and confidentiality}

The participants' confidentiality had been maintained throughout the research studies. During the research process the questionnaires were stored in a lock and key protected cupboard. And the data were entered in a password protected computer. The questionnaires had been handed over to the Department of Community and Family Medicine at the end of the research and they will be discarded in a proper manner.

\section{Budget}

This was a self-funded study. 


\section{6. $\quad$ Results}

A total of 120 participants were interviewed among the selected population and all of them responded to the whole interview. The overall response rate was $100 \%$.

Table 1 Socio-demographic characteristics of study participants $(n=120)$

\begin{tabular}{|c|c|c|c|}
\hline Demographic & Characteristics & Count (n) & Percentage (\%) \\
\hline \multirow[t]{2}{*}{ Sex } & Female & 50 & $\overline{41.7}$ \\
\hline & Male & 70 & 58.3 \\
\hline \multirow{4}{*}{$\begin{array}{c}\text { Age Category } \\
\text { (Years) }\end{array}$} & $13-19$ & 17 & 14.2 \\
\hline & $20-35$ & 32 & 26.7 \\
\hline & $36-60$ & 49 & 40.8 \\
\hline & above 60 & 22 & 18.3 \\
\hline \multirow[t]{3}{*}{ Marital status } & Married & 74 & 61.7 \\
\hline & Unmarried & 39 & 32.5 \\
\hline & Others & 7 & 5.8 \\
\hline \multirow[t]{4}{*}{ Educational level } & Up to grade 5 & 22 & 18.3 \\
\hline & Grade 6 to 11 & 73 & 60.8 \\
\hline & Advanced Level & 18 & 15.0 \\
\hline & Diploma or higher & 7 & 5.9 \\
\hline
\end{tabular}

Under the demographic factors gender, marital status, age and education level were considered. Respondent characteristics $(n=120) 70$ were males $(58.3 \%)$ while females were 50 in number $(41.7 \%)$. In the selected population $81(67.5 \%)$ were married and the rest 39(32.5) were unmarried. Out of the selected population majority of the people came under the middle-aged category which was 49(40.8\%), while adolescents, young adults and elderly people were 17(14.2\%), 32(26.7\%), 22(18.3\%) respectively. 
Characteristics of Study population according to level of pain immediately after fracture

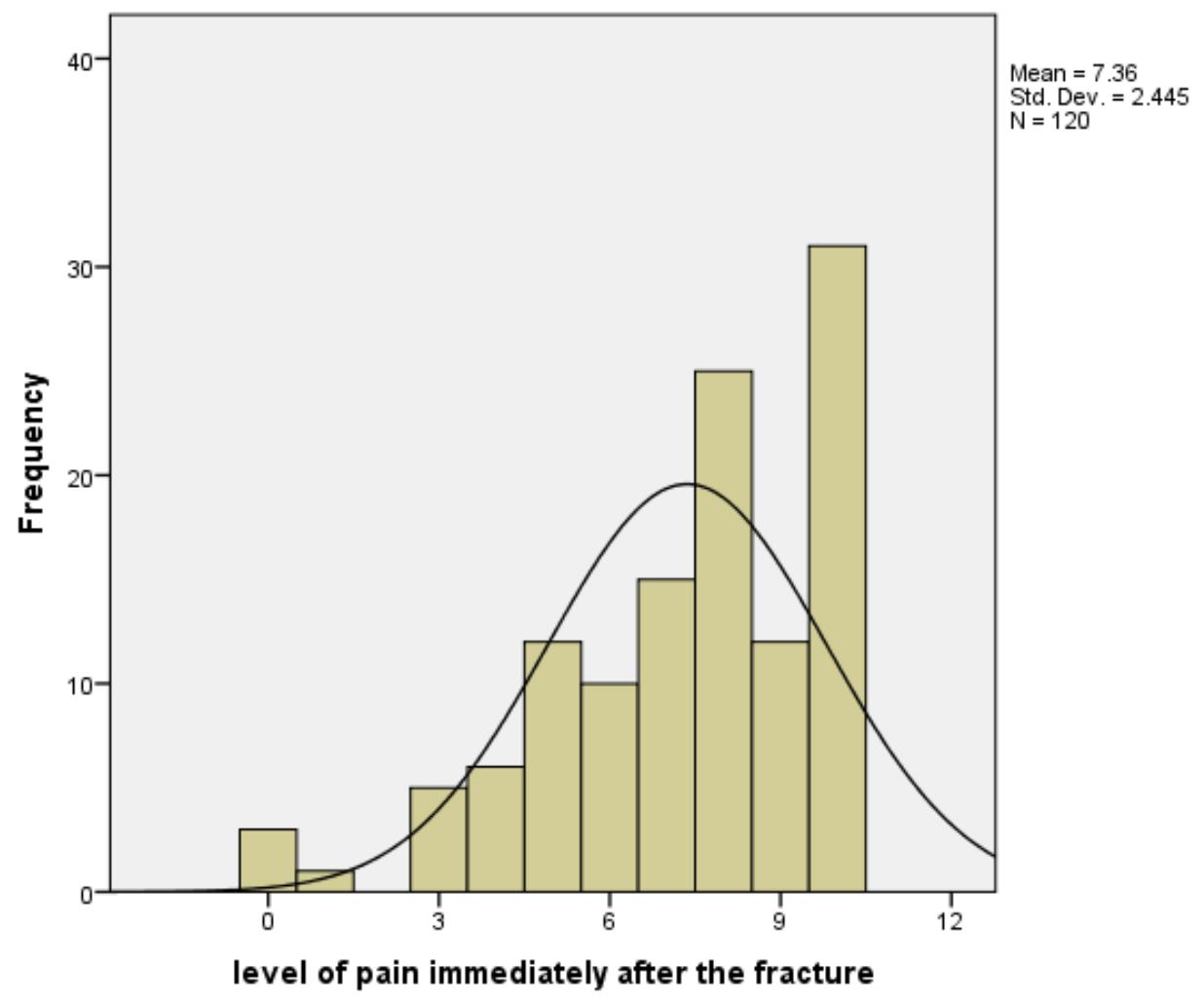

Figure 1 Distribution of level of pain immediately after fracture

The histogram shows distribution skewed to the left (skewness $=-0.96$ ) and the median pain score after fracture is $8 .(\mathrm{IQR}=6-10)$

According to the level of pain immediately after the fracture majority of males $(n=48)$ had severe pain, and majority of females $(n=42)$ experienced severe pain. Majority of married patients $(n=63)$ had severe pain immediately after the fracture. Majority of unmarried patients $(n=26)$ also experienced severe pain immediately after the fracture. 
Characteristics of Study population according to level of pain you had one hour after the administration of analgesics

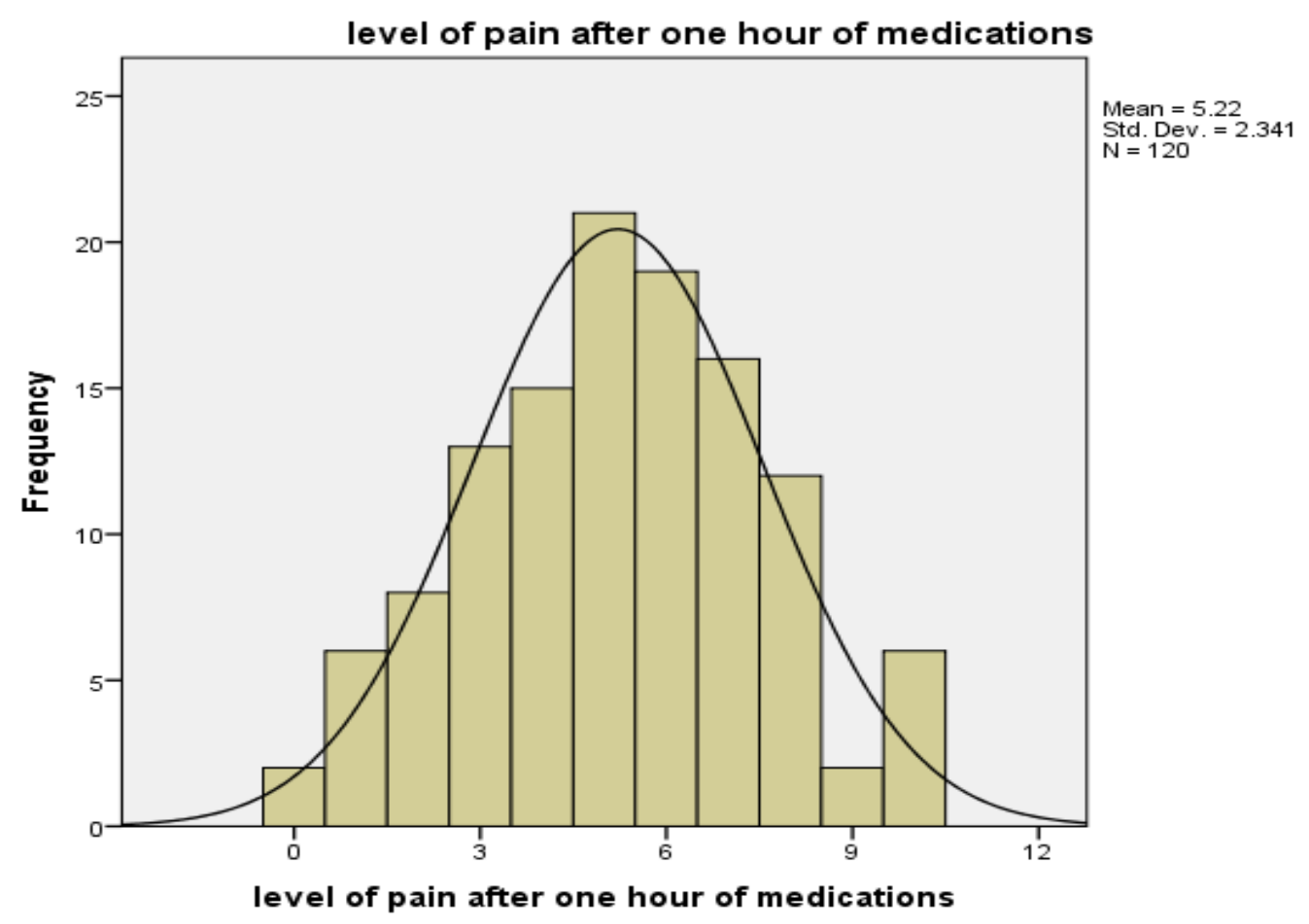

Figure 2 Distribution of level of pain 1 hour after analgesics

The median pain score has reduced to 5.00(IQR=4-7) after one hour of analgesic administration. Majority of male patients $(n=28)$ had moderate pain one hour after the analgesics and also majority of female patients $(n=27)$ also had moderate pain after one hour using analgesics. 
Characteristics of Study population according to level of pain you had following nonmedical management ${ }^{1}$

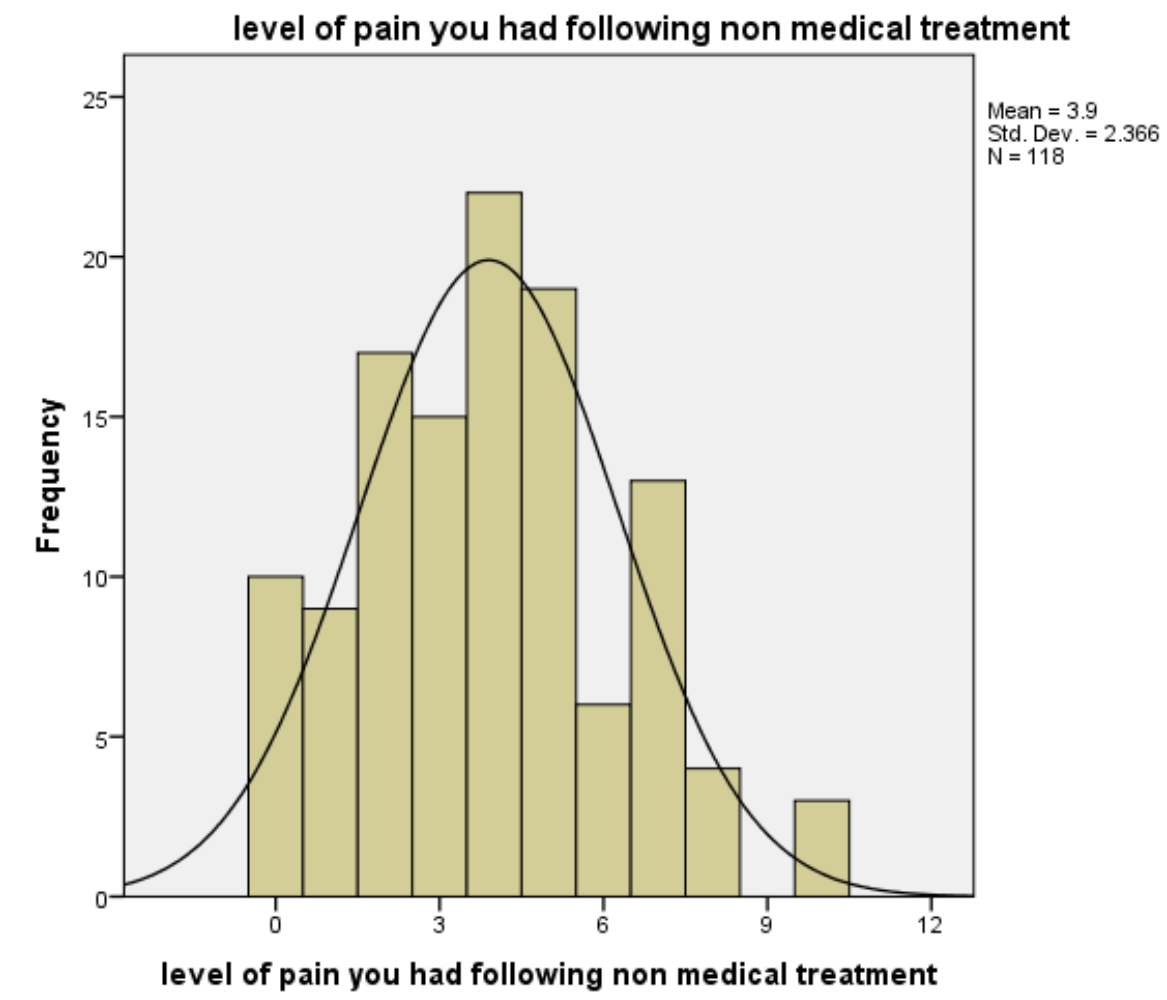

Figure 3 Distribution of level of pain after non-medical intervention

The median pain score further reduced to $4(\mathrm{IQR}=2-5)$ after nonmedical intervention which was done after analgesic administration. Both male and female categories had moderate pain after non-medical treatment. All the other age categories had moderate pain following non-medical treatment except adolescents who had mild pain.

\footnotetext{
${ }^{1}$ Non-medical intervention includes all the management done except analgesics administration
} 


\section{Level of perceived satisfaction with the pain management among patients with fractures of long bones in general surgical wards and orthopedic wards of Teaching Hospital}

Jaffna.

Table 2 Characteristics of perceived satisfaction $(n=120)$

\begin{tabular}{|c|c|c|c|c|}
\hline \multirow{3}{*}{ Characteristics of patient satisfaction } & Very & Moderately & Moderately & Very \\
\hline & Dissatisfied & Dissatisfied & Satisfied & Satisfied \\
\hline & $\%$ & $\%$ & $\%$ & $\%$ \\
\hline
\end{tabular}

\begin{tabular}{|c|c|c|c|c|c|c|c|c|c|}
\hline $\begin{array}{l}\text { Information about your pain treatment } \\
\text { option }\end{array}$ & 3 & 2.5 & 17 & 14.4 & 78 & 65.5 & 21 & 17.6 & 119 \\
\hline Route of administration of medication & 2 & 1.7 & 1 & 0.8 & 71 & 59.2 & 46 & 38.3 & 120 \\
\hline How often you take your medication & 1 & 0.8 & 1 & 0.8 & 74 & 61.7 & 44 & 36.7 & 120 \\
\hline Amount of pain medication you take & 2 & 1.7 & 3 & 2.5 & 78 & 65.0 & 37 & 30.8 & 120 \\
\hline $\begin{array}{l}\text { The time that it takes your pain } \\
\text { medication to work }\end{array}$ & 2 & 1.7 & 12 & 10.0 & 71 & 59.2 & 35 & 29.1 & 120 \\
\hline $\begin{array}{l}\text { The way your physician treated your } \\
\text { pain }\end{array}$ & 2 & 1.7 & 3 & 2.5 & 61 & 50.8 & 54 & 45.0 & 120 \\
\hline $\begin{array}{l}\text { The care (attentiveness and sensitivity) } \\
\text { provided by the nurses for your pain } \\
\text { management }\end{array}$ & 2 & 1.8 & 2 & 1.8 & 62 & 55.4 & 46 & 41.0 & 112 \\
\hline $\begin{array}{l}\text { The level or amount of pain relief } \\
\text { provided by your pain medication }\end{array}$ & 1 & 0.8 & 10 & 8.4 & 73 & 60.8 & 36 & 30.0 & 120 \\
\hline $\begin{array}{l}\text { The duration of pain relief provided by } \\
\text { your pain medication }\end{array}$ & 1 & 0.8 & 13 & 10.9 & 70 & 58.9 & 35 & 29.4 & 119 \\
\hline Medical staff answering your questions & 1 & 1.1 & 3 & 3.4 & 57 & 64.0 & 28 & 31.5 & 89 \\
\hline $\begin{array}{l}\text { The medical staff providing pain } \\
\text { medication when you request }\end{array}$ & 1 & 4.0 & 4 & 16.0 & 12 & 48.0 & 8 & 32.0 & 25 \\
\hline
\end{tabular}




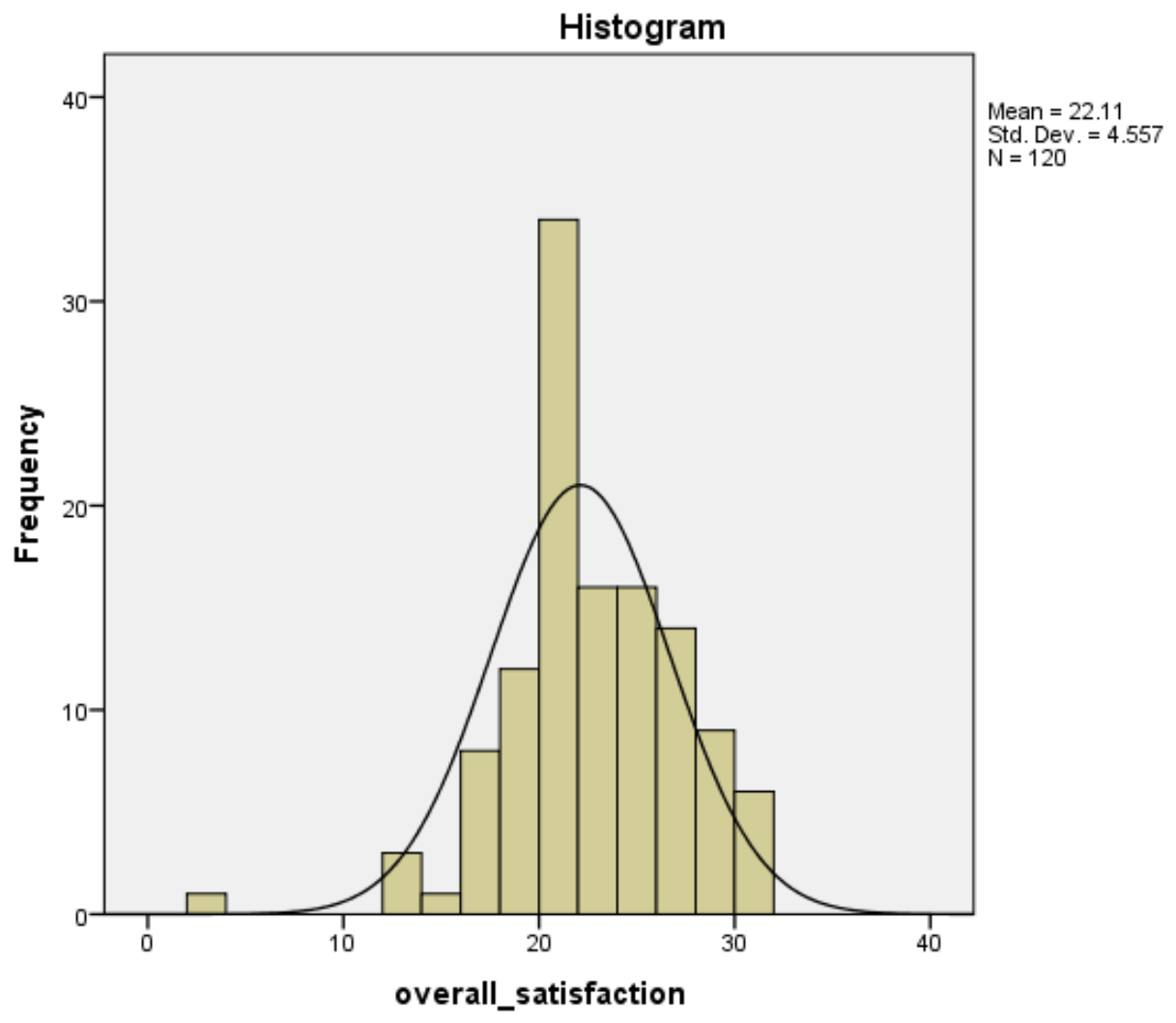

Figure 4 Distribution of patient perceived satisfaction score

This chart indicates that most of the patients $(\mathrm{N}=81)$ with fractures of long bones in general surgical wards and orthopedic wards of Teaching Hospital Jaffna were "moderately satisfied"(17-25) with the pain management. (Mean=22.11, Skewness $=-0.4$ )

Table 3 Association between patient care with satisfaction $(n=120)$

\begin{tabular}{|c|c|c|c|c|c|c|c|c|}
\hline & & $\mathrm{N}$ & $\begin{array}{c}\text { Percentage } \\
(\%)\end{array}$ & $\begin{array}{c}\text { Mean } \\
\text { Satisfaction } \\
\text { score }\end{array}$ & $\begin{array}{c}\text { Std. } \\
\text { Deviation }\end{array}$ & $\begin{array}{c}\text { Mean } \\
\text { difference }\end{array}$ & $\begin{array}{c}95 \% \text { confidence } \\
\text { interval }\end{array}$ & $\mathrm{p}$ Value \\
\hline Doctor discussed & No & 62 & 51.7 & 21.8 & 3.869 & 0.6 & -2.2 to 1.1 & 0.48 \\
\hline $\begin{array}{l}\text { the importance of } \\
\text { treatment for pain }\end{array}$ & Yes & 58 & 48.3 & 22.4 & 5.211 & & & \\
\hline Informed to notify & $\mathrm{No}$ & 59 & 49.2 & 21.3 & 3.801 & 1.7 & -3.2 to 0.01 & 0.051 \\
\hline $\begin{array}{l}\text { the staff when you } \\
\text { experience the pain }\end{array}$ & Yes & 61 & 50.8 & 23 & 5.092 & & & \\
\hline
\end{tabular}

Out of the total sample size, 62(51.7\%) patients responded "no" to "physician discussed that treatment for pain is important and the rest 58(48.3\%) patients responded "yes".

There was no statistical significance on whether doctor discussed on treatment or not on patient satisfaction. $(\mathrm{p}=0.48)$ 
Out of the total sample size, 59(49.2\%) patients were told to notify the staff when they experienced pain and the rest 61(50.8) of the patients weren't. Though mean satisfaction was higher in patients who were informed to notify the staff when they experienced the pain, it was not statistically significant.

\section{Association between socio-demographic factors and level of perceived satisfaction with pain management among patients with fractures in long bones.}

Table 4 Association between socio-demographic factors and level of perceived satisfaction $(n=120)$

\begin{tabular}{|c|c|c|c|c|c|c|c|}
\hline $\begin{array}{l}\text { Socio } \\
\text { demographic features }\end{array}$ & Characteristics & $\mathbf{N}$ & $\begin{array}{l}\text { Mean } \\
\text { Satisfaction } \\
\text { score }\end{array}$ & $\begin{array}{l}\text { Standard } \\
\text { deviation }\end{array}$ & $\begin{array}{l}\text { Mean } \\
\text { differenc }\end{array}$ & $\begin{array}{c}95 \% \\
\text { e Confidence } \\
\text { Interval }\end{array}$ & $\begin{array}{c}\mathbf{P} \\
\text { value }\end{array}$ \\
\hline \multirow[t]{2}{*}{$\overline{\text { Gender }}$} & Female & 50 & 21.5 & 3.7 & -1.0 & -2.7 to 0.6 & 0.218 \\
\hline & Male & 70 & 22.5 & 5.1 & & & \\
\hline \multirow[t]{4}{*}{ Age } & $13-19$ & 17 & 22.2 & 5.3 & & & 0.935 \\
\hline & $20-35$ & 32 & 21.7 & 5.3 & & & \\
\hline & $36-60$ & 49 & 22.4 & 4.1 & & & \\
\hline & above 60 & 22 & 22.0 & 4.0 & & & \\
\hline \multirow[t]{5}{*}{ Education } & Up to grade 5 & 22 & 22.7 & 4.8 & & & 0.130 \\
\hline & Grade 6 to 11 & 73 & 22.4 & 4.6 & & & \\
\hline & Advanced level & 18 & 19.7 & 3.9 & & & \\
\hline & Diploma or & 7 & 22.5 & 4.2 & & & \\
\hline & Higher & & & & & & \\
\hline \multirow[t]{2}{*}{ Marital Status } & Married & 74 & 22.7 & 4.1 & -1.5 & -3.3 to 0.3 & 0.095 \\
\hline & $\begin{array}{l}\text { Unmarried } \\
\text { and Others }\end{array}$ & 46 & 21.2 & 5.2 & & & \\
\hline
\end{tabular}

An independent sample t-test was done to determine the effect of gender and marital status on patient satisfaction. The results showed males were more satisfied $(M=22.5)$ than females $(M=21.5)$ and married $(M=22.7)$ were more satisfied than others $(M=21.2)$, but no significant difference. There was no significant association between gender as well as marital status with perceived level of satisfaction with pain management among patients with fractures in long bones.

A one-way ANOVA was performed to compare the effect of age category on patient satisfaction. 
It revealed that there was not a statistically significant difference in patient satisfaction between at least two groups $(\mathrm{F}(3,116)=[0.142], \mathrm{p}=[0.935])$.

The ANOVA results of educational level and patient satisfaction conveyed that there was no significant association between educational level and perceived satisfaction with pain management among patients with fractures in long bones. $(F(3,116)=[1.920], p=[0.130])$

\section{Association between health-related factors and level of perceived satisfaction with pain management among patients with fractures in long bones.}

Table 5 Overall level of perceived satisfaction among patients who have past medical history $(n=120)$

\begin{tabular}{cllccccc}
$\begin{array}{c}\text { Health related } \\
\text { factors }\end{array}$ & Characteristics & $\mathrm{N}$ & $\begin{array}{c}\text { Mean } \\
\text { Satisfacti } \\
\text { on score }\end{array}$ & $\begin{array}{c}\text { Standard } \\
\text { deviation }\end{array}$ & $\begin{array}{c}\text { Mean } \\
\text { difference }\end{array}$ & $\begin{array}{c}\text { Confidence } \\
\text { Interval }\end{array}$ & $\begin{array}{c}\mathrm{p} \\
\text { value }\end{array}$ \\
\hline Past medical history & Not present & 91 & 22.1 & 4.606 & 0.0 & -1.9 to 2.0 & 0.958 \\
& Present & 29 & 22.1 & 4.480 & & & \\
Past surgical history & Not present & 93 & & 4.783 & 1.0 & -0.7 to & 0.29 \\
& Present & 27 & 22.3 & 3.653 & & 2.8 & 5
\end{tabular}

An independent sample t-test was conducted to evaluate the effect of past medical history on means of satisfaction which is summarized in the above table shows there is no significant association between past medical history and the perceived satisfaction with pain management among patients with fractures in long bones. $(\mathrm{p}=0.958)$

Table 6 Individual association of comorbidities $(n=120)$

\begin{tabular}{lcccccc}
$\begin{array}{l}\text { Past Medical } \\
\text { History }\end{array}$ & N Satisfaction & $\begin{array}{c}\text { Mean } \\
\text { score }\end{array}$ & $\begin{array}{c}\text { Standard } \\
\text { deviation }\end{array}$ & $\begin{array}{c}\text { Mean } \\
\text { difference }\end{array}$ & $\begin{array}{c}\text { 95\% Confidence } \\
\text { Interval }\end{array}$ & $\begin{array}{c}\mathrm{p} \\
\text { Value }\end{array}$ \\
\hline Diabetes Mellitus & 16 & 23.1 & 4.3 & -1.2 & -3.6 to 1.3 & 0.326 \\
Heart Disease & 11 & 22 & 3.7 & 0.1 & -2.5 to 2.7 & 0.923 \\
Others & 15 & 21 & 4.5 & 1.3 & -1.4 to 3.9 & 0.324 \\
\hline
\end{tabular}

Individual association of comorbidities with patient satisfaction was checked by an individual t-test and it came up statistically insignificant. 
The t-test of past surgical history and means of satisfaction gave $\mathrm{p}$ value of 0.295 ; hence there was no significant association between past surgical history and perceived satisfaction with pain management among patients with fractures in long bones.

Table 7 Overall level of perceived satisfaction among patients according to fracture site

\begin{tabular}{|c|c|c|c|c|c|c|c|c|}
\hline $\begin{array}{l}\text { Site of } \\
\text { Fracture }\end{array}$ & $\mathrm{N}$ & $\begin{array}{c}\text { Percentage } \\
(\%)\end{array}$ & $\begin{array}{l}\text { Present } \\
\text { (mean) }\end{array}$ & $\begin{array}{c}\text { Not } \\
\text { Present } \\
\text { (mean) }\end{array}$ & $\begin{array}{l}\text { Standard } \\
\text { Deviation } \\
\text { (present) }\end{array}$ & $\begin{array}{c}\text { Mean } \\
\text { differenc } \\
\mathrm{e}\end{array}$ & $\begin{array}{c}95 \% \\
\text { Confidence } \\
\text { Interval }\end{array}$ & $\begin{array}{c}\mathrm{p} \\
\text { Value }\end{array}$ \\
\hline Humerus & 11 & 7.8 & 21.5 & 22.2 & 3.4 & 0.7 & -2.2 to 3.6 & 0.620 \\
\hline Radius & 59 & 41.8 & 22.9 & 21.4 & 4.5 & -1.5 & -3.1 to 0.2 & 0.081 \\
\hline Ulna & 19 & 13.5 & 22.9 & 21.9 & 3.6 & -1 & -3.2 to 1.3 & 0.415 \\
\hline Femur & 7 & 5.0 & 22.1 & 22.1 & 2.8 & 0.0 & -3.6 to 3.5 & 0.984 \\
\hline Tibia & 16 & 11.3 & 22.4 & 22.1 & 4.4 & -0.3 & -2.7 to 2.1 & 0.803 \\
\hline Fibula & 13 & 9.2 & 23.3 & 21.9 & 4.0 & -1.4 & -4.0 to 1.3 & 0.317 \\
\hline Hip & 3 & 2.1 & 19.0 & 22.2 & 3.6 & 3.2 & -2.1 to 8.5 & 0.233 \\
\hline Clavicle & 13 & 9.2 & 18.8 & 22.5 & 6.5 & 3.7 & 1.2 to 6.3 & 0.005 \\
\hline
\end{tabular}

Individual t-tests were done on each site of fracture to assess any significance on patient satisfaction and patients without clavicle fracture had significant association with patient satisfaction. $(\mathrm{p}=0.005)$

Table 8 Overall level of perceived satisfaction among patients according to non-medical intervention done $(\mathrm{n}=120)$

\begin{tabular}{lcccccccc} 
Management & N $\begin{array}{r}\text { Percentage } \\
(\%)\end{array}$ & $\begin{array}{r}\text { Yes } \\
\text { (mean }\end{array}$ & $\begin{array}{c}\text { No } \\
\text { (mean } \\
\text { Score) }\end{array}$ & $\begin{array}{c}\text { Score) } \\
\text { (yes) }\end{array}$ & $\begin{array}{c}\text { Mean } \\
\text { Difference }\end{array}$ & $\begin{array}{c}\text { 95\% Confidence } \\
\text { Interval }\end{array}$ \\
\hline POP Cast & 93 & 77.5 & 22.6 & 20.6 & 4.3 & -2 & -0.4 to -0.1 & 0.049 \\
Sling & 20 & 16.7 & 21.7 & 22.2 & 4.2 & 0.5 & -1.7 to 2.8 & 0.624 \\
Traction & 5 & 4.2 & 19 & 22.2 & 2.7 & 3.2 & -0.9 to 7.3 & 0.120 \\
No & 2 & 1.6 & 14 & 22.3 & 15.6 & 8.3 & -14.5 to -2.0 & 0.011
\end{tabular}

Intervention 
Patients who had undergone any non-medical intervention had a significant association with patient satisfaction. $(\mathrm{p}=0.011)$ and patient with POP cast also had statistically significant association with patient satisfaction. $(\mathrm{p}=0.049)$

\begin{tabular}{|c|c|c|c|c|c|c|}
\hline $\begin{array}{l}\text { Were medications } \\
\text { given within ten } \\
\text { minutes of admission }\end{array}$ & $\mathrm{N}$ & $\begin{array}{c}\text { Mean } \\
\text { Satisfaction } \\
\text { score }\end{array}$ & Std. Deviation & $\begin{array}{c}\text { Mean } \\
\text { Difference }\end{array}$ & $\begin{array}{c}95 \% \\
\text { Confidence } \\
\text { Interval }\end{array}$ & $\mathrm{p}$ Value \\
\hline \multirow{2}{*}{ No } & \multirow{2}{*}{67} & \multirow{2}{*}{21.37} & \multirow{2}{*}{3.996} & & -3.3 to - & \\
\hline & & & & 1.67 & 0.03 & 0.046 \\
\hline Yes & 53 & 23.04 & 5.069 & & & \\
\hline
\end{tabular}

An independent sample t-test was conducted to compare the level of perceived satisfaction with acute pain management in patient who received analgesics within ten minutes of admission and those who did not. There was a significant difference in the scores for within 10 minutes $(\mathrm{M}=23.04, \mathrm{SD}=5.07)$ and not within 10 minutes $(\mathrm{M}=21.37, \mathrm{SD}=4)(\mathrm{p}=0.046)$

\section{Discussion}

A descriptive cross sectional study was conducted on patients with fractures in long bones who had undergone interventions in general surgical and orthopedic wards of Teaching Hospital, Jaffna (total 120 participants). To our knowledge this study is among few studies conducted on patients' satisfaction with pain management among orthopedic patients. The findings of this study were helpful to assess the level of perceived satisfaction with acute pain management and to describe the influence of socio demographic and health related factors on the level of perceived satisfaction with pain management among patients with fractures in long bones in ward 24 of Teaching Hospital Jaffna.

Firstly, our study showed that, $67.5 \%$ of the study population were moderately satisfied with the pain management. It concluded around two thirds of our patients were satisfied with the pain management even when they reported considerable levels of pain. We assumed that effective pain relief would correlate highly with patients' satisfaction with pain management. Accordingly, on beforehand we assessed the level of pain immediately after the fracture, one hour after the administration of analgesics and following non-medical management. At the time of interview majority had experienced severe pain according to the level of pain immediately after the fracture (median pain score $=8$ ), then we had identified that majority had moderate 
pain one hour after using analgesics (median pain score=5) and finally the pain further reduced (median pain score=4) following non-medical management which was done after analgesic administration. Above statistically significant improvement in pain score might be one of the reasons for high overall satisfaction levels.

Literatures have revealed that patient satisfaction was the frequently used, non-specific measure of outcomes. Assessment of patient satisfaction is an important tool for monitoring the quality of care in hospitals. It is most frequently obtained by patient reports of perceptions of satisfaction through surveys and interviews similar to the one we used in our study. Despite the high satisfaction scores in our study, we identified some shortcomings and influencing factors which need to be addressed with the aim of formulating and implementing strategies for improvement.

A cross sectional study was conducted in Lebanon to evaluate the presence and effectiveness of acute pain management targeting two different populations, in which among the orthopedic patients $10.7 \%$ were dissatisfied with the pain management. Also, they found that the dissatisfied patients were those who did not have their pain assessed, those who were not informed to report it when in pain and those who did not receive pain medications on time.

Similarly, in our study, $48.3 \%(\mathrm{~N}=58)$ of the study population, said that the doctor had discussed about the pain and treatment for pain is important. Patient-clinician communication is a necessary component of effective pain management as every aspect of pain management relies on communication: assessing pain, deciding on pain management, implementing treatment plans and assessing the effectiveness. Though more than half, 51.7\% (N=62) did not have an effective discussion with the doctor, we know little about how clinicians are working hard to manage all patients. Thus, this finding will be helpful in how it might be improved to produce better patient outcomes. Likewise, another study that was done in South Africa involving 270 patients with long bone fractures found that only $2 \%$ of patients were not asked about the pain intensity while $18 \%$ were asked initially by a nurse.

In our study, around 51\% of fracture patients were asked to notify when they experienced pain. Though it was statistically not significant $(\mathrm{p}=0.051)$, mean satisfaction was higher in patients who were informed to notify the staff when they experienced pain. This is in congruence with previous study that was done in America, which indicated that nursing care, physician care and hospital facilities were not equally influential on patient satisfaction on pain management and suggested to improve nursing and staff care to provide more direct care for patients with pain. The timely provision of pain management, early administration of analgesics might have played a role in defining the level of patients' perceived satisfaction. As in our study, we found 
there was notably higher satisfaction among those who received the medications within 10 minutes of admission ( $M=23.04)$ compared to those who weren't received within 10 minutes $(M=21.37)(p=0.046)$. This is in congruence with previous literature that was done in two tertiary care hospitals on 2017 recruiting a part of orthopedic patients as well, found that around $85 \%$ of the patients were satisfied with their pain management and can be explained by the fact that only $7.7 \%$ of the patients had to wait for more than 30 minutes before getting the pain medication.

In our study only $7.5 \%$ and $0.8 \%$ of the study population were moderately dissatisfied and very dissatisfied respectively with acute pain management. Among eleven parameters we asked regarding the satisfaction part we found that the dissatisfied patients were those who didn't have adequate pain relief with their pain medication: time taken for the pain medication to work, the level of pain relief provided by the pain medication, duration of pain relief and those who did not receive information about pain treatment.

Prescribed pain medication plays an important role in patient satisfaction. Careful selection of the available pain medications are the best hope for the provision of optimal pain relief to the patient. A study carried out among thirty American and thirty Dutch patients after operative treatment of ankle fractures revealed that patients who used non opioid pain medication reported less pain and greater satisfaction with the pain relief than the patients managed with opioid pain medication. Likewise, another study said, after operative fracture treatment patients who took more opioids reported greater pain intensity and less satisfaction with pain relief and greater self-efficacy was the best determinant of satisfaction with pain relief. Even though in our study we didn't analyze the type of analgesics given and their efficacy in pain relief, one point that can be readily explained is there is a strong association between the types of analgesics given and patients' satisfaction.

Giving adequate information on pain treatment to patients is one of the vital factors that influences patient satisfaction with the pain management. A study was carried out in 24 patients with clavicle fracture in Netherlands stated that informing patients about their injury, treatment options and expectations for recovery were paramount for overall patient satisfaction.

Furthermore, satisfaction is a subjective feeling, also dependent upon patients' expectations regarding pain management. Patients' expectations have a strong effect on the degree of patients' satisfaction with an experience. This can be explained by our study as we found that more than two thirds of the patients reported that their overall pain relief met their expectations of pain relief. And it correlated with overall patient satisfaction. 
Regarding socio-demographic influences on the level of perceived satisfaction with acute pain management among patients with fractures of the long bones, we considered mainly gender, age, marital status and educational level.

Out of the 120 patients, 70 were males and the rest were females. The majority of both males $(\mathrm{N}=48)$ and females $(\mathrm{N}=42)$ experienced severe pain immediately after the fracture. Another finding we identified was, that the majority of both males $(\mathrm{N}=28)$ and females $(\mathrm{N}=27)$ had moderate pain one hour after using analgesics and both males $(\mathrm{N}=25)$ and females $(\mathrm{N}=22)$ had moderate pain after nonmedical treatment as well. Finding of this study regarding gender on patient satisfaction illustrate, males were more satisfied $(M=22.54)$ than females $(M=21.5)$ and this finding was not statistically significant because p-value was 0.218.

In our study, out of selected population majority of the patients were under 36-60 years of age and they were more satisfied than other age groups (mean score=22.39) while 20 -35 years age category patients were less satisfied $(M=21.72)$. But there was no significant association between age category and perceived satisfaction with pain management because the p-value was 0.935 . Another finding of the study regarding age category was in every category majority of the patients' experienced severe pain immediately after the fracture. Also, we found that majority of 13-19 years age category patients had mild pain while the other all age categories had moderate pain one hour after analgesic administration. Another finding was, all the other age categories had moderate pain following nonmedical treatment except 13-19 years age category patients who had mild pain.

A study that was done on perceived control mediates relationship between pain severity and patient satisfaction, found experience and expectations influenced the level of satisfaction. As older people have more experience and less expectations, they were more satisfied than younger people. Harvard Medical School, USA performed a study on socio demographic characteristics to their satisfaction with medical care showed that the satisfaction was significantly associated with greater age and less education and Age was the strongest demographic factor for pain satisfaction. Another study on the influence of expectations and actual pain experiences on satisfaction with postoperative pain management in 191 patients, they found that main characteristics of dissatisfied patients were young age and female sex. Conversely, a previous study that was done on patient satisfaction and demographic characteristics in Tehran had been given a clue that younger patients were more satisfied with health services than older ones.

Out of selected population under the educational category, majority represented the educational level from grade 6 to GCE O/L. In each educational category the majority were moderately 
satisfied and results showed that there was no significant association between educational level and perceived satisfaction with pain management $(\mathrm{p}=0.130)$. Accordingly a similar study was done to identify factors associated with satisfaction with care in cancer patients undergoing ambulatory treatment, level of education was not associated with satisfaction scores, although other reports had shown that a higher level of education was associated with higher expectations as regards of quality of care.

Furthermore, our study results revealed, out of studied population majority were married ,also it showed that majority of both married and others had severe pain immediately after the fracture. Another factor, the study had revealed that all married and others experienced moderate pain after using analgesics. Under the marital status on patient satisfaction, there was no significant association found $(\mathrm{p}=0.095)$. Literatures revealed patient satisfaction varied with socio demographic factors (age, gender, employment status, and marital status).

Thus, according to our study results there is no significant association between socio demographic factors such as age, gender, educational level, marital status and patients' perceived satisfaction with the pain management.

Regarding influence of health-related factors on the level of perceived satisfaction with acute pain management among patients with fractures of long bones, we had considered mainly about past medical history and past surgical history of the patient. In our study population, most of the patients didn't have either a past medical history $(\mathrm{N}=102)$ or a past surgical history $(\mathrm{N}=93)$. We found that there was no significant association between past medical history and perceived satisfaction with pain management among patients with fractures in long bones $(p=0.953)$, almost similar mean satisfaction scores for both with and without a past medical history. Moreover, among those with past medical history we assessed individual association of comorbidities (diabetes mellitus, heart disease and others) with patient satisfaction by individual $\mathrm{t}$ test, though it also came up statistically insignificant, compared to other comorbidities those with Diabetes mellitus exhibit greater satisfaction scores. Similarly, we found that there is no significant association between past surgical history and perceived satisfaction with pain management among patients with fractures in long bones $(p=0.295)$. A study conducted on the impact of comorbidities on perioperative outcome of hip fractures in geriatric population, showed that fractures usually occur in patients who had preexisting medical problems or comorbidities and comorbidity had influenced on treatment and prognosis of the condition. Similarly, another study done in Ethiopia stated there may be an association between previous surgical history and patient satisfaction. 
Furthermore, we assessed the level of perceived satisfaction according to the fracture site and found that there was a significant association between patients without clavicle fracture and patients' satisfaction with pain management $(\mathrm{p}=0.005)$, as patients without clavicle fracture exhibit high level of satisfaction compared to those with clavicle fracture. A previous study done among patients with displaced mid shaft clavicle fracture revealed, informing patients about their injury, treatment options and expectations for recovery are paramount for overall patient satisfaction and also direct operative management led to higher patient satisfaction. The lack of satisfaction may be due to inadequate analgesics and sling applied in an improper way. Also, we have addressed the overall level of perceived satisfaction according to nonmedical intervention done for fracture management. Majority of our study population patients had POP cast $(\mathrm{N}=93)$ compared to either sling or traction as nonmedical intervention and our data indicated that patients with POP cast had statistically significant association with patient satisfaction ( $\mathrm{p}=0.049)$; they exhibited greater satisfaction with the pain management as it might be due to more effective immobilization.

\section{Conclusion}

In our study, $24.2 \%$ of the study population were very satisfied and $67.5 \%$ were moderately satisfied with acute pain management. So the majority of the patients were satisfied with acute pain management even though they reported considerable levels of pain.

We could see some obvious reasons for the satisfaction of a greater number of patients regarding acute pain management. $48.3 \%$ of patients said doctors discussed pain and pain treatment was important in patient care. More satisfaction was observed among the patients who were discussed regarding the importance of pain treatment. So, doctor-patient communication regarding pain management and the knowledge of patients regarding pain treatment were some of the determining factors of patient satisfaction.

Higher satisfaction scores were also observed among the patients who were asked to notify health staff when they experienced pain. So, the care of patients given by the health staff was also another factor determining patient satisfaction.

Majority of the patients had severe pain immediately after a fracture while moderate pain following the administration of analgesics and mild pain after the non-medical intervention following analgesic administration. Analgesic administration and non-medical intervention both effectively reduced the pain of patients. This significant reduction in pain levels and early analgesics administration were the reasons for higher overall satisfaction among patients. 
When we consider the site of fracture and patient satisfaction, the patients without clavicle fracture were more satisfied than the patients with clavicle fracture. We found a significant association between patient's satisfaction and patients with clavicle fracture.

When we consider non-medical interventions, patients who underwent any of the non-medical interventions were more satisfied than the patients who did not undergo any non-medical interventions. So non-medical intervention was also another important factor in determining the patient satisfaction. Among the non-medical interventions, the patients who had a pop cast applied were more satisfied than the patients who did not have a pop cast applied.

$7.5 \%$ of the participants were moderately dissatisfied and $0.8 \%$ were very dissatisfied. The dissatisfied population were very few compared to the satisfied population. The main reason for the dissatisfaction of patients was that they could not get adequate pain relief with their pain medication.

There was no association between gender, age category, educational level, marital status, past medical history, past surgical history and patient's perceived satisfaction with acute pain management. In our community the patient's expectations regarding acute pain management were lesser than western community. So, most patients were satisfied with acute pain management. That is why we were not able to find any association between socio-demographic factors, health related factors and patient's perceived satisfaction with acute pain management even though in foreign studies they have found significant association between sociodemographic factors, health related factors and patient's perceived satisfaction with acute pain management.

\section{Recommendations}

The importance of assessing and managing pain has become paramount in today's hospital environment. Effective pain management results in improved patient outcomes and increased patient satisfaction. So proper assessment of pain severity, improved interventions and interdisciplinary approach can enhance patients' perceived satisfaction. In addition to practicing nationally accepted guidelines for pain management, it is crucial to develop more reliable and valid measures in practice in improving a variety of patient outcomes. Our study suggests Satisfaction with acute pain management among fracture patients depend on a number variables including patient related factors, patients' expectations, promptness of acute pain management service response, the effectiveness of treatment and health care professionals' attitudes. So further studies are needed to explore the factors influencing patient satisfaction with acute pain management, particularly in Sri Lanka. Also, researches have to be conducted 
on the impact of pain education on patient satisfaction with pain management. We also recommend improving the care given to clavicle fracture patients as well as implementing a system to reduce the waiting time for analgesics. We also suggest recording the pain scale on different occasions to tailor the analgesics given. It would be better if we improved doctor patient relationships and effective communication with patients on pain management.

\section{Limitation}

This study was able to assess the level of perceived satisfaction with acute pain management and the influence of socio-demographic and health related factors among patients with fractures in long bones in general surgical wards and orthopaedic wards of Teaching Hospital Jaffna. However, there were some limitations. To start with, there were no researches on the level of perceived satisfaction on acute pain management among fracture patients done in Sri Lanka. Even though the estimated sample size was 427, we could only collect data from 120 people due to the reduced number of patients as a result of the current covid-19 crisis.

During the data collection, some people could not understand certain questions in the questionnaire and some people did not pay serious attention to the questions. For example, in the pain and pain medication part of the questionnaire people faced difficulties in scoring the level of pain. There might be differences in the accuracy of recalling the pain level by the participants. For example pain level immediately after the fracture and one hour after administration of analgesics. As we interviewed the patients only after the acute intervention, there could be recall bias during the data collection. Due to reduced mobility of the fracture patients, they were unable to get direct access to health care staff for their needs, so there had to be a middle man (bystander) in between patient and health care staff. In such circumstance the patient did not have a clear perception regarding the attention given by the health care workers. As the investigators were medical students who are under the health care system, patients were reluctant to come up with the actual information regarding pain management and their perceived satisfaction because of lack of confidentiality.

When considering the selected population of the research only patients above 12 years of age were included and only the population from the Teaching Hospital of Jaffna was considered but, there may be certain differences in pain management among hospitals due to the varying health facilities such as human resources and non-human resources. Due to the covid-19 pandemic, the given time for data collection was not adequate. In developing the literature there was difficulty in accessing a large range of scientific literatures. 


\section{Reference}

1. Adhikari, Mukesh, Paudel, Raj, Narendra, Mishra, Raj, Shiva, Shrestha, Archana, Upadhyaya, \& Prasad, D. (2021). Patient satisfaction and its socio-demographic correlates in a tertiary public hospital in Nepal: a cross-sectional study. BMC Health Services Research, 21(1), 135. https://doi.org/10.1186/s12913-021-06155-3

2. Aldossari, K., K., Shubair, M., M., Al-Zahrani, Jamaan, Alduraywish, A., Abdulrahman, Alahmary, Khalid, Bahkali, Alwa, S, Aloudah, M., Sara, Almustanyir, Sami, ... Ashraf. (2020). Association between Chronic Pain and Diabetes/Prediabetes: A Population-Based Cross-Sectional Survey in Saudi Arabia. Pain Research and Management, 2020. https://doi.org/10.1155/2020/8239474

3. Awolola, A. M., Campbell, L. and Ross, A. (2015) 'Pain management in patients with longbone fractures in a district hospital in KwaZulu-Natal, South Africa', African Journal of Primary Health Care and Family Medicine, 7(1). doi: 10.4102/phcfm.v7i1.818.

4. Batbaatar, Enkhjargal, Dorjdagva, Javkhlanbayar, Luvsannyam, Ariunbat, Savino, Mario, Matteo, Amenta, \& Pietro. (2017). Determinants of patient satisfaction: A systematic review. In Perspectives in Public Health (Vol. 137, Issue 2, pp. 89-101). SAGE Publications Ltd. https://doi.org/10.1177/1757913916634136

5. Bizuneh, Belay, Yosef, Lema, Fitiwi, Girmay, Fentie, Yilkal, Demeke, Woldegerima Berhe, Y., Ophtahe, Ashagrie, Enyew, \& Henos. (2020). Assessment of Patient's Satisfaction and Associated Factors regarding Postoperative Pain Management at the University of Gondar Compressive Specialized Hospital, Northwest Ethiopia. Pain Research and Management, 2020. https://doi.org/10.1155/2020/8834807

6. Bot, G.J., Arjan, Bekkers, Stijn, Arnstein, M., P., Smith, Malcolm, R., Ring, \& David. (2014). Opioid use after fracture surgery correlates with pain intensity and satisfaction with pain relief. Clinical Orthopaedics and Related Research, 472(8), 2542-2549. https://doi.org/10.1007/s11999-014-3660-4

7. Breivik, H.Borchgrevink, Allen, Rosseland, P. C., M., S., Romundstad, L. A., Hals, L. B., Kvarstein, E. K., \& G.Stubhaug, A. (2008). Assessment of pain. In British Journal of Anaesthesia (Vol. 101, Issue 1, pp. 17-24). Oxford University Press. https://doi.org/10.1093/bja/aen103

8. Eberly, L., Richter, D., Comerci, G., Ocksrider, J., Mercer, D., Mlady, G., Wascher, D. and Schenck, R. (2018). Psychosocial and demographic factors influencing pain scores of patients with knee osteoarthritis. PLOS ONE, 13(4), p.e0195075. 
9. Evans, C.J., Trudeau, E., Mertzanis, P., Marquis, P., Peña, B.M., Wong, J. and Mayne, T. (2004). Development and validation of the pain treatment satisfaction scale (ptss): a patient satisfaction questionnaire for use in patients with chronic or acute pain. Pain, 112(3), pp.254266.

10. Farrokhi, Pouria, Hashjin, Aghaei, A., Bagherzadeh, Zarei, R., \& Ehsan. (2020). Predictors of Patient Satisfaction; Quality Dimensions and Demographic Characteristics. https://doi.org/10.21203/rs.3.rs-32162/v1

11. Glowacki, D. (2015) 'Effective pain management and improvements in patients' outcomes and satisfaction', Critical Care Nurse, 35(3), pp. 33-41. doi: 10.4037/ccn2015440.

12. Gordon, B., D., Polomano, C., R., Pellino, A., T., Turk, C., D., McCracken, M., L., Sherwood, G., Paice, J. A., Wallace, M. S., Strassels, S. A., \& Farrar, J. T. (2010). Revised american pain society patient outcome questionnaire (aps-poq-r) for quality improvement of pain management in hospitalized adults: Preliminary psychometric evaluation. Journal of Pain, 11(11), 1172-1186. https://doi.org/10.1016/j.jpain.2010.02.012

13. Hashemi, Masoud, Seyed, Rohanifar, Ramin, Azarfarin, Rasoul, Razavi, Sajjad, Seyed, Momenzadeh, \& Sirous. (2016). A comparison of the sociodemographic and clinical characteristics of patients referring to a pain clinic with subacute and chronic pain. Anesthesiology and Pain Medicine, 6(6), 39373. https://doi.org/10.5812/aapm.39373

14. Helmerhorst, G. T. T., Lindenhovius, A. L. C., Vrahas, M., Ring, D., \& Kloen, P. (2012). Satisfaction with pain relief after operative treatment of an ankle fracture. Injury, 43(11), 19581961. https://doi.org/10.1016/j.injury.2012.08.018

15. IASP Terminology - IASP (2017). Available at: https://www.iasppain.org/Education/Content.aspx.

16. Joel, Afolayan, A., Deborah, Oyeleye, I., Falilat, Adebiyi, Omowumi, Abiola, Durojaiye, Omowumi, \& Donald, B. (2015). Factors influencing perception of pain among clients attending a Nigeria teaching hospital. International Journal of Nursing and Midwifery, 7(8), 133-140. https://doi.org/10.5897/ijnm2015.0174

17. Menzies, B., I., Mendelson, A., D., Kates, L., S., Friedman, \& M., S. (2012). The Impact of Comorbidity on Perioperative Outcomes of Hip Fractures in a Geriatric Fracture Model. Geriatric Orthopaedic Surgery \& Rehabilitation, 3(3), 129-134. https://doi.org/10.1177/2151458512463392

18. Nguyen, France, T. V., Bosset, François, Jean, Monnier, Alain, Fournier, Jacqueline, Perrin, Valérie, Baumann, Cédric, Brédart, Anne, \& Mercier, M. (2011). Determinants of patient satisfaction in ambulatory oncology: A cross sectional study based on the OUT-PATSAT35 
questionnaire. BMC Cancer, 11(1), 526. https://doi.org/10.1186/1471-2407-11-526

19. Otani, Koichiro, Chumbler, R., N., Herrmann, A., P., Kurz, \& S., R. (2015). Impact of Pain on Patient Satisfaction Integration Process. Health Services Research and Managerial Epidemiology, 2, 233339281561510. https://doi.org/10.1177/2333392815615103

20. Pellino, T. A. and Ward, S. E. (1998) 'Perceived control mediates the relationship between pain severity and patient satisfaction', Journal of Pain and Symptom Management, 15(2), pp. 110-116. doi: 10.1016/S0885-3924(97)00255-8.

21. Ramia, Elsy, Nasser, C, S., Salameh, Pascale, Saad, \& Hanna, A. (2017). Patient Perception of Acute Pain Management: Data from Three Tertiary Care Hospitals. Pain Research \& Management, 2017, 7459360. https://doi.org/10.1155/2017/7459360

22. Roozekrans, Margot, Schrier, V. Der, Rutger, Aarts, Leon, Sarton, Elise, Velzen, Van, Monique, Niesters, Marieke, Dahan, Albert, \& Olofsen, E. (2018). Benefit versus severe side effects of opioid analgesia: Novel utility functions of probability of analgesia and respiratory $\begin{array}{llll}\text { depression. } & \text { Anesthesiology, } & \text { 932-942. }\end{array}$ https://doi.org/10.1097/ALN.0000000000002138

23. Schulz, A. and Jerosch, J. (2007) 'Perioperatives Schmerzmanagement in der Orthopädie', Der Orthopäde, 36(1), pp. 32-40. doi: 10.1007/s00132-006-1026-7.

24. Svensson, I., Sjöström, B. and Haljamäe, H. (2001) 'Influence of expectations and actual pain experiences on satisfaction with postoperative pain management', European Journal of Pain, 5(2), pp. 125-133. doi: 10.1053/eujp.2001.0227.

25. Tawil, S., Iskandar, K. and Salameh, P. (2018) 'Pain management in hospitals: Patients' satisfaction and related barriers', Pharmacy Practice, 16(3), pp. 1-9. doi: 10.18549/PharmPract.2018.03.1268.

26. Tosun, B., Aslan, O. and Tunay, S. (2018) 'Preoperative position splint versus skin traction in patients with hip fracture: An experimental study', International Journal of Orthopaedic and Trauma Nursing, 28, pp. 8-15. doi: 10.1016/j.ijotn.2017.07.002.

27. Tutuhatunewa, D., E. S., Dams, M., Son, O. C. Van, Louhanepessy, J., Krabbe, R. D., F.M., P., Postma, J., M., \& Diercks, R. L. (2020). Exploring patient satisfaction after operative and nonoperative treatment for midshaft clavicle fractures: A focus group analysis. $B M C$ Musculoskeletal Disorders, 21(1), 1-9. https://doi.org/10.1186/s12891-020-03557-y

28. Uri, Ofir, Elias, Shlomo, Behrbalk, Eyal, Halpern, \& Pinchas. (2015). No gender-related bias in acute musculoskeletal pain management in the emergency department. Emergency Medicine Journal, 32(2), 149-152. https://doi.org/10.1136/emermed-2013-202716

29. Venn, S. and Fone, D. L. (2005) 'Assessing the influence of socio-demographic factors and 
health status on expression of satisfaction with GP services', Clinical Governance, 10(2), pp. 118-125. doi: 10.1108/14777270510594290.

30. Wang, K., Dowrick, A., Choi, J., Rahim, R. and Edwards, E. (2010). Post-operative numbness and patient satisfaction following plate fixation of clavicular fractures. Injury, 41(10), pp.1002-1005.

31. Weiss, G. L. (1988) 'Patient satisfaction with primary medical care: Evaluation of sociodemographic and predispositional factors', Medical Care. doi: 10.1097/00005650198804000-00007.

32. Young, G. J., Meterko, M. and Desai, K. R. (2000) 'Patient satisfaction with hospital care: Effects of demographic and institutional characteristics', Medical Care. doi: 10.1097/00005650-200003000-00009. 